\title{
One size fits not quite all: Universal research ethics with diversity
}

2018, Vol. 14(3) I-17

(C) The Author(s) 2017

Article reuse guidelines: sagepub.com/journals-permissions DOI: 10.1।77/I747016II7739939 journals.sagepub.com/home/rea

@SAGE

\section{Mohamed S Msoroka}

University of Waikato, New Zealand; Muslim University of Morogoro, Tanzania

\section{Diana Amundsen}

University of Waikato, New Zealand

\begin{abstract}
For researchers in Aotearoa New Zealand who intend to conduct research with people, it is common practice to first ensure that their proposals are approved by a Human Research Ethics Committee (HREC). HRECs take the role of reviewing, approving or rejecting research proposals and deciding on whether the intended research will be completed in the 'right', rather than the 'wrong' way. Such decisions are based upon a system which is guided by universal ethical principles - principles that assume there is universal agreement about the ethically right way to conduct research. Increasingly, Aotearoa New Zealand is becoming more culturally diverse. Actions that are assumed as 'right' in reference to ethical norms endorsed in one culture or society may not always be considered 'right' in reference to ethical norms in another culture or society. In this article we first set out what is already known in the literature about the origins and applications of universal ethics in a research context. Next, we analyse how cultural values and beliefs bear influence on the process of ethical deliberation. Two case studies illustrate our own examples of how conducting ethical research projects following universal principles with cultural diversity operated in practice. We conclude that one size fits not quite all. Lastly, we propose that Aotearoa New Zealand HRECs may need to consider expanding their approach from universal ethical principles to include a more diverse interpretation of what is 'ethical research conduct'. Rather than advocating a radical approach, i.e. either universality or diversity, it is time for HRECs to
\end{abstract}

\section{Corresponding author:}

Mohamed Salum Msoroka, Te Whiringa School of Educational Leadership \& Policy, Faculty of Education, University of Waikato, Private Bag 3105, Hamilton, 3240, New Zealand.

Email: Msm24@students.waikato.ac.nz 
consider a hybrid approach of universality with diversity that permits partial detour from universal principles when considering ethics application proposals.

\section{Keywords}

ethics, human research ethics committees, universalism, cultural diversity, universal research ethics

\section{Introduction}

What makes something the 'right', rather than the 'wrong' thing to do? Ethics is about how people should live in the right way. Fromm (2006: 18) advocates that, 'humanistic ethics is the applied science of "the art of living" based upon the theoretical science of man'. In a research context, ethics is about how research should be completed in the right way - ethical research conduct. Western ethics is often thought to contain universal principles that are norms that apply to all people in all places, times and contexts. A norm that is not universalisable is considered nonethical (Nordenstam, 1968). Almost two decades ago, the ethicist Carl Coon (1998) explained that social groups have a tendency to view their own internal ethical standards as universal, absolute and right; therefore when other groups' standards differ, these are viewed as abnormal or wrong standards. Coon (1998) considered that ethical standards were used as a core method of socially grouping humans together, or socially dividing humans apart, simultaneously preserving unity within their own group.

More recently, new perspectives are being developed (such as situated ethics) based on exploration of how ethical issues are practically handled by educational researchers in the field (Simons and Usher, 2012). Debates continue to centre on the question of the applicability of universal ethics. Yet, if there can be acceptance that morality is culture-driven rather than universal, then the question of ethics may be seen in a different (and humbler) light. Although universal ethical principles have conventionally been accepted as valid and applicable in all situations, we argue that different research practices may necessitate ethical principles becoming mediated, enabling the adoption of different meanings in relation to those practices. This notion differs from applying cultural relativism in ethical judgments: 'Radical cultural relativism would hold that culture is the sole source of the validity of a moral right or rule. Radical universalism would hold that culture is irrelevant to the validity of moral rights and rules, which are universally valid' (Chandler and Munday, 2016: 400). The stance taken in this article is that neither radical cultural relativism nor radical universalism approaches are prudent.

Instead, this article is positioned where ethical principles meet ethical practices in research, and endeavours to illustrate the application of universal ethical principles with diversity that permits partial detour from universal principles. This 
article does not intend to define complex terms such as ethics and morality, and here, both terms are used synonymously. These authors propose an approach that accepts the tension between, and the strengths of, both cultural relativism and universalism. Using our experience, we demonstrate how universalism with diversity operated in the context of research practice.

Commonly, in Aotearoa New Zealand, researchers who intend to conduct research with humans must first ensure that their proposals are approved by a Human Research Ethics Committee (HREC). HRECs take the role of reviewing, approving or rejecting proposed studies, and monitoring on-going projects to ensure that they follow the international and locally accepted ethical guidelines (World Health Organisation, 2009). Such decisions are based upon a system guided by universal ethical principles - principles that assume there is universal agreement about the ethically right way to conduct research. As with many other nations, Aotearoa New Zealand is increasingly becoming more culturally diverse (Singham, 2006; Statistics NZ, 2013). In this regard, it is noteworthy that actions that are assumed as 'right' in reference to ethical norms endorsed in one culture or society may not always be considered 'right' in reference to ethical norms in another culture or society (Melé and Sánchez-Runde, 2013). We propose that one size fits not quite all.

Consider, for example, African society. African moral thought is based on the natural sociality of human beings and sets a social/communitarian ethic, rather than an individual ethic. 'Individualistic ethics that focus on the welfare and interests of the individual is hardly regarded in African moral thought' (Gyekye, 2010: 8). According to the social ethic that is core to African culture, social and community life carries a heavy sense of duty for individuals with respect to their community and its members. This elevated notion of 'duty to others' in African contexts has a similar status to the notion of 'individual rights' in Western ethics. Ethically, in Africa, responsibilities to the community over-rule individual rights, not the other way round as seen in Western ethics. This morality is also seen in other cultures. Tanida (1996: 201) points out that in Japanese thought, 'a person does not exist as an individual that is as an autonomous unit, but only as a member of the family, community, or society. In this society, an act is "good" and "right" when it is commonly enacted; it is "bad" and "wrong" if nobody else does it'. New Zealand Māori researcher Mika (2015) notes differences between indigenous Māori and Western moral thought. He explains that the ethics of Western academic research demand a distance between self and 'thing', both in intention and in practice. This very requirement may be fraught for Māori, ' ... because of an ethics involved with things in the world that Western researchers do not tend to identify' (Mika, 2015: 61). Thus, researchers wishing to work across diverse cultures may encounter ethical challenges in some situations.

In this article, two doctoral researchers evaluate the challenges they faced in applying universal ethical principles when researching with cultural diversity and the steps they took to expand into a more diverse interpretation of ethical conduct. 
The two case studies illustrate efforts to navigate the inherent tension of researching with culturally diverse populations within the boundaries of universal ethical principles. Using the literature around universal ethical principles, we analyse and compare our experiences of partial detour from universal principles to include cultural diversity while adhering to ethical research conduct. Hudson (2004) and Berghan (2007) suggest that universal approaches to ethics fail to recognise the impact that cultural difference has on the application of ethical principles. A tension exists for researchers needing to research with communities where local or cultural ethical norms are in conflict with universal ethical principles, which are the principles that must be adhered to by the researcher in order to gain HREC approval for their project (Melé and Sánchez-Runde, 2013). In the context of a rapidly growing multicultural environment, questions must be raised around how helpful a universalistic ethical approach is when researching with cultural diversity.

\section{Universalism}

Universal ethics refers to moral principles that are universally accepted and practiced (Mutenherwa and Wassenaar, 2014). In a research context, universalism denotes an ideology that Western research methods and methodologies are applicable in all geographic, social and cultural contexts. Whether or not ethics are universal has been debated in many different cultures and societies (International Theological Commission, 2009) by thinkers such as Plato, Aristotle, Mencius, Rousseau, Kant, Darwin, Nietzsche, Freud and Gilligan (Singer, 1994). Following the aftermath of the Second World War, global debates were sparked around the issues of the basic rights a human citizen is entitled to. In 1948, to ensure that the horrific Second World War human rights abuses would never again occur, a basic international human rights and ethics instrument (the Universal Declaration of Human Rights (UDHR)) was accepted across nations globally (Johnson and Symonides, 1998). This eight page document sets out, for the first time, fundamental human rights to be universally protected. Translated into over 500 languages, it lists 30 Articles (short paragraphs). United Nations member states pledged themselves to achieve, '...the promotion of universal respect for and observance of human rights and fundamental freedoms...' (United Nations, 2015: 2). Significantly, countries around the globe accepted a universal ethics instrument (International Theological Commission, 2009).

In one way or another, research ethics are connected with the UDHR. For example, Article 3 of the UDHR states: 'Everyone has the right to life, liberty and security of person' (UN, 2015). This resulted in one of the fundamental research ethics principles requiring researchers to protect the life of their study participants. Researchers are required not to endanger or harm human life (World Medical Association, 2008). Another example is found in Article 6: 'Everyone has the right 
to recognition as a person before the law' (UN, 2015). This means that the human dignity of every individual must be recognised, and is one element of agreed research ethics principles (WMA, 2008). Article 12 protects the privacy of people (UN, 2015), another key research ethics principle (WMA, 2008). In addition, Article 19 grants freedom of opinion and expression to all people, including freedom to hold that opinion (UN, 2015). This is the basis for study participants' voluntary participation in research and the requirement for researchers to seek informed consent from participants (WMA, 2008).

Paving the way, the UN's UDHR later led researchers to develop a declaration now known as a 'landmark document for research ethics and for the protection of human subjects' (Brody, 2010: 97). In Helsinki, Finland, in June 1964, the 18th World Medical Association (WMA) General Assembly signed the Declaration of Helsinki (DoH), which represented 'a universal standard for the conduct of research and human subject care' (Blackmer, 2010: 91). The DoH became the foundation of research ethics and of the protection of human subjects. It is assumed to govern researchers in research activities (Marshall, 2007). The DoH assumes notions of what is 'correct and ethical' research, presuming that there is universal agreement upon the acceptable way to engage in knowledge construction. The document has come to be regarded as the 'global ethical standards by which all researchers were expected to abide' (Blackmer, 2010: 93). Since the mid-1960s, both the UDHR and the DoH have been the most influential set of principles upon which most Westernised countries base their ethical code of conduct when researching with human subjects, including prisoners (Institute of Medicine, 2007; The National Commission for the Protection of Human Subjects of Biomedical and Behavioral Research, 1976).

In summary, based on the $\mathrm{DoH}$, the primary ethical obligation of any researcher working with humans is that the well-being of the individual research subject must take precedence over all other interests. Each research participant must be informed of the research aims, methods, benefits, risks and institutional affiliations of the researcher, as well as the right to refuse to participate in the research, or to withdraw consent at any time without reprisal. Notably, the researcher must seek the research subject's freely-given informed consent, preferably in writing. If consent cannot be expressed in writing, the non-written consent must be formally documented and witnessed. Lastly, a significant influence arising from the $\mathrm{DoH}$ was the resolve to submit all research proposals to an independent review committee before the study begins. As such, many research institutions in the Western world, largely the universities and higher education research centres, set up Human Research Ethics Committees (HRECs) to ensure that the rights and interests of human subjects are protected (Battin et al., 2014; Blackmer, 2010). Furthermore, the UK's 2011 changes to the Governance Arrangements for Research Ethics Committees (GAfREC II) challenges HRECs to make their protocols more transparent in the public domain (Edwards, 2012). 
HRECs are guided by the DoH, which is seen to represent a universal standard for the conduct of research with humans. 'Assurance of scientific integrity, appropriateness and utility of research, and protection of human subjects are at the core of ethical principles to be upheld regardless of the geographic location where research is conducted' (Blackmer, 2010: 91). It is also evident that, since the 1960s, however, as new forms of research have come into being, research ethics are becoming more complex (Brody, 2010). Indeed, in some cases, it has necessitated researchers to depart from the codes of the DoH (McMillan and Conlon, 2004). These complexities require consideration; increasingly, research is conducted across many countries and cultures, some of whose understanding and interpretation about informed consent may differ from others.

\section{Universality with diversity}

The role of ethics and the degree of transparency of the personal values held by researchers have undergone changes in the field of social science research as the Western world has progressed. The emerging new paradigm in the twenty-first century challenges researchers to keep pace with evolving research methods and the underpinning ethics, which allow (or inhibit) research to be inclusive of cultural diversity. In a multicultural society, the values from one single culture cannot be assumed as the values for all. Berghan (2007: 13) states that 'multiculturalism accepts that ethical principles are relative and are contextually bound rather than absolute'. If ethics can be related to a culture's values and beliefs, then it could be said that cultural values must bear influence on the process of ethical deliberation. To be clear, however, our proposal of universality with diversity differs from the notion of cultural relativism within ethical deliberations. Donnelly (1984) describes cultural relativism on a continuum from strong to weak, where strong cultural relativism presumes culture as the primary basis for the validity of a moral right or ethical judgment. Weak cultural relativism accepts that culture may be important to the validity or a moral right, but recognises universal human rights as the overriding rule. Universality with diversity argues for an approach that preserves the tension and insights of both universalism and relativism in order to proactively empower emancipatory research.

Indigenous Māori researchers (Coram, 2011; Smith, 1999; Tauri, 2014) have spoken out about the need to value diversity in research ethics and, significantly, in relation to indigenous research, that the researcher decolonise the research. These findings stem from a history of damaging consequences arising from research projects conducted on indigenous communities that were developed within a dominant Western research approach. Koster et al. (2012) call for decolonisation of research by moving away from methods that maintain traditional ways of working on indigenous communities towards engaging in research 
that is completed with and for indigenous communities. Continuing to develop indigenous research paradigms and processes that focus on empowering their institutions and communities is paramount (Koster et al., 2012; Tauri, 2014). To do this, the research must be based on ethics that respect and value the community as a full partner in the co-creation of the research question and process. Tauri goes as far as saying that diversity should be valued above universality, stating that, '...ethical research must begin by replacing Eurocentric prejudice with new premises that value diversity over universality' (Tauri 2014: 147). Tauri's (2014) concern is that HRECs tend to privilege Eurocentric notions of what constitutes ethical research conduct, therefore reviewing, approving or rejecting research proposals based on principles that elevate the status of 'individual rights'. In so doing, research processes that empower communitarian or social principles valued by some cultures are marginalised. According to Nygard and Saus, HRECs 'often overlook the external and collective risk involved in research projects and do not acknowledge diversity among groups...' (Nygard and Saus, 2016: 670). They found that when there is no consideration of culture and context in the institutionalisation of ethics, the ethical considerations depend solely on the personal ethics and morals of researchers in the field.

Melé and Sánchez-Runde (2013) note the tension between universal ethics and local values and norms. Simultaneously, they raise the point that, particularly in a global world, ethics in culturally diverse and global environments may necessitate the opening of closed attitudes. We propose a hybrid approach of universality with diversity and illustrate how this was attempted in two current research projects.

\section{Methodology}

A qualitative research approach was employed. The main aim was to investigate how a hybrid approach of universality with diversity that permits partial detour from universal principles might operate in practice. The investigation ran over fifteen months and was conducted in three phases. During the first phase, each doctoral student recorded issues encountered when applying for ethics consent from the HRECs that were in some contention with universal ethical principles (e.g. written informed consent). In phase two, tensions that were encountered between universal research ethical principles and diversity as they arose in the field were documented using field and reflective notes. Because the two studies were conducted in two different cultural settings, we subsequently compared our ethics experiences that we had undergone in the field. Focus was given on ethics diversities that emerged and how we accommodated them to proactively empower emancipatory research through partial detour from universal ethics. In order to develop a summary related to each project, we noted down everything we thought important. Then in the third and final phase, we examined how our experiences 
agreed and/or diverged from existing accounts in the literature of ethical diversity, as presented in this text.

\section{Case study I}

\section{Research ethics committees - A Tanzanian context}

Just as in the Western world, Africa is not immune from the abuses of human research, especially in medical studies. Evidence of such abuses has been documented in various African countries (Ndebele et al., 2014). For instance, in Zimbabwe in the 1990s, Dr Richard Gladwell was charged with murder after conducting unethical human experiments that led to six deaths. In Nigeria in 2001, 11 children of the control group died when the Pfizer Pharmaceutical Company was trialling the antibiotic trovafloxacin (Ahmad, 2001; Ndebele et al., 2014). Some of the survivors suffered permanent brain impairment. Later, it was reported that the research project was not approved by the local HREC.

With such unethical research impacts as well as the influence of more Western countries wanting to research with African communities, African countries have been developing policies and regulations, and establishing HRECs to monitor and control research activities. HRECs have become more common, but for some decades they have been stronger in the medical field than in social science research practice. In South Africa, for example, the South African Medicines Control Council (MCC) was established in 1965 by the Medicines and Related Substances Act, 1965 (Act no. 101 of 1965) to regulate and control research activities in the health sector (Ndebele et al., 2014). Shortly after, the first health research ethical review in the African context was recorded in South Africa (Ndebele et al., 2014); the University of Witwatersrand was the first academic institution in Africa to establish a health HREC in 1966. Yet there are still many African countries that do not have registered HRECs (Mokgatla et al., 2017). It is noteworthy that the Republic of South Africa considers prisoners to be among the vulnerable groups (The Republic of South Africa, 2015). Therefore, South African health HRECs are urged to ensure the participation of prisoners in research is voluntary (Davies and Karstaedt, 2012; The Republic of South Africa, 2015).

In Tanzania, the National Institute for Medical Research (NIMR) was established in 1979 by the Parliament Act No. 23 of 1979 to regulate and coordinate health research (Ndebele et al., 2014). In 2002 NIMR established the National Health Research Ethics Review Committee (NHRERC), which operates under the Medical Research Coordinating Committee (MRCC) (Ikingura et al., 2007). The NHRERC is responsible for overseeing ethical review and approving health research in the country. Recently, NIMR centres - Mwanza, Amani, Muhimbili, Tabora and Tukuyu - have formed local HRECs to decentralise ethical clearance activities in order to save time and exercise more local control. These HRECs 
assess institutional research proposals and forward their recommendations to NHRERC for further ethical review (Ikingura et al., 2007).

Although universities in Tanzania pledge their commitment to maintaining research ethics, HRECs are not as common in social science research efforts. Most of the Tanzanian higher learning institutions do not have HRECs; St. Johns University of Tanzania, however, recently reported establishing a HREC in 2013 (St Johns University of Tanzania, 2013). Its performance has yet to be determined. Those who undertake social science research projects involving humans may seek permission from various university offices such as the Directorate of Postgraduate Research, the Directorate of Research and Publications, the Office of the Vice Chancellor, etc. Yet, commonly, social science research proposals are not submitted to HRECs. In most cases, it is the researcher's personal ethical principles that guide the study while the researcher is in the field.

Whilst the UN's UDHR and the DoH principles are available to guide the establishment of African RECs, the underlying African moral thought is based on a social/communitarian ethic, rather than an individual ethic (Mkhize, 2006; Onuoha, 2007; Wasunna et al., 2014). In Africa, including Tanzania, ethical obligations to the tribe, village and community come before a person's individual rights. In this context, the application of Western ethics principles may present challenges for African HRECs.

\section{Ethical diversities - The Tanzanian principle of social ethics}

In the Western worldview (including that of New Zealand) informed consent is a matter of an individual participant being autonomous in deciding whether to participate in research or not (Mutenherwa and Wassenaar, 2014; Wasunna et al., 2014). With 'informed consent', researchers demonstrate their respect towards human study participants (Wasunna et al., 2014). As per the principles from the DoH, a researcher must seek the research subject's freely-given informed consent, preferably in writing. If consent cannot be expressed in writing, the non-written consent must be formally documented and witnessed (Blackmer, 2010). There may be some challenges with this approach to informed consent in the Tanzanian context, however, where society is based on a society/communitarian ethos, and characterised by poverty and illiteracy (Wasunna et al., 2014). In Africa, and Tanzania in particular, decisions and knowledge are usually developed from social negotiations. In this regard, decision making involves discussion of the issue at hand with family members, and sometimes with the bigger community, to find consensus (Mkhize, 2006; Onuoha, 2007; Wasunna, et al., 2014). This is the centre of African communal life. Therefore, 'informed consent' in the Tanzanian context may need to reflect a similar process. Study participants may need to involve various individuals in arriving at a communally or community based, perhaps even orally granted, 'informed' consent (Mkhize, 2006). Yet this may be 
perceived as not meeting the ethical principles of correct research conduct by a HREC using a process that is underlined by a universal system of ethics, which views informed consent as individualistic (Wasunna et al., 2014).

Sometimes, poverty and high illiteracy characteristics of the research participants in countries such as Tanzania increase the gap between participants' views and beliefs regarding the problem and those of the researchers (Wasunna et al., 2014). In this situation, it is difficult to follow the universal approach to an informed consent process as participants and researchers may not share the same perspective, especially when a researcher is required by an institution to gain individually written informed consent. Hence, 'in order to ensure meaningful informed consent, researchers have to understand the cultures and beliefs of the communities from which they recruit research participants' (Wasunna et al., 2014: 58). Furthermore, because of the African communitarian ethos (Wasunna et al., 2014), it is common to find Tanzanians discussing and sharing the events of research meetings. In this context, research privacy and confidentiality as discussed from a Western worldview (WMA, 2008) may be seen to be at a crossroads.

\section{Mohamed's research ethics case}

The first case presented here is based on a project that is being conducted by a Tanzanian doctoral research student (Mohamed), enrolled and studying at a New Zealand university. His research focuses on prison education in a Tanzanian context. Mohamed's qualitative study employs multiple case studies, in which five Tanzanian prisons were studied. Study participants included 16 prisoners who took part in educational programmes, 12 inmates who did not, and seven of the programmes' teachers (one prison staff member and six prisoners) as well as various other prison education stakeholders. The following examples illustrate universal principles meeting with diversity in research ethics as practised by Mohamed.

While in the field one day, two of Mohamed's study participants met after he finished interviewing one of them. Those participants knew each other well and were comfortable with each other. While Mohamed was around, the two started discussing things related to participating in Mohamed's study. Some topics were related to previous interviews. In the Western view, discussing the events from study interviews out of the interview context is very much discouraged. Such discussion violates the privacy and confidentiality of the research participants, which is one of the key research ethical principles (WMA, 2008). In African communal life, however, this is not a problem (Mkhize, 2006; Onuoha, 2007; Wasunna et al., 2014) so long as people have mutual trust. Mohamed did not interrupt their conversation because he understood the cultural context. If he had interfered and stopped their discussion by explaining the need for confidentiality, there was a possibility that the two participants would lose trust in him, and interpret his study negatively. Mohamed did not want to develop a mistrustful environment for his participants. 
Universal research ethical principles require researchers to seek informed consent from research participants individually (Mutenherwa and Wassenaar, 2014; Wasunna et al., 2014; WMA, 2008). In the second scenario, considering that most of the information in Mohamed's study was collected in prisons, which may be regarded as "total institutions" ", it was not possible to seek individual consent, except from a few inmates on a few occasions. On most occasions, the only possibility was to meet prisoners in groups. Therefore, Mohamed explained in detail about his study to those groups and let them decide whether to participate or not. Whenever he presented the focus and purpose of the study, the prisoners took some time to discuss among themselves before they decided whether to participate. In the Western view, this might be seen as unethical because of the insistence of individualistic informed consent (Wasunna et al., 2014). In the African context, however, such as that of Tanzania, communally based 'informed' consent is common and viewed as having nothing wrong with it (Mkhize, 2006). Study participants felt happy and empowered to find a chance to communally share their experience in prison education. Therefore, Mohamed tried as much as he could to conduct his study according to the Tanzanian cultural context - 'situated' ethics (Simons and Usher, 2012) - and at the same time not to divert very much from the New Zealand HREC commitments. Improvising on the spot in the field, Mohamed conducted his research following the universal principles of research ethics and adjusted to the cultural diversity of the situation at hand. This is an example of research using universalism with diversity.

\section{Case Study 2}

\section{New Zealand research ethics committees - Principle of no harm}

A key ethical principle upheld by New Zealand HRECs is that human beings have the right to be treated as ends in themselves and never as a means to an end. No harm must be done to an individual. HRECs' processes do not easily allow researchers to give participants a say in how research is to be conducted. On one hand, a researcher may endeavour to use an inclusive research approach to safeguard that research participants are treated as ends, not as means, but on the other hand a researcher may not be entitled to share very much of the responsibility with the researched. This presents an inherent conflict. Either participants are being subjected to a form of manipulative coercion, or research participants are perceived to be undermining the integrity of the researcher's academic proficiency. Wilson and Wilks comment about the limitations of Australian research institutions' ethical approval process for researchers working with indigenous communities, saying, 'while the process may aim to protect indigenous populations from exploitation, it fails to acknowledge the proactive role of indigenous communities in research' (Wilson and Wilks, 2013: 145). This could also be the case in New Zealand. 
In a New Zealand context, Tolich (2016) believes that, in the wake of the Cartwright Commission, New Zealand universities and health HRECs operate as risk managers who have 'come to manage the risk involved in cultural sensitivity to such an extent that (they) may unwittingly harm the subjects they seek to protect' (Tolich, 2002: 166). Some authors argue that research should aim not simply to spare people from harm, but to empower them as the creators of knowledge (Coram, 2011; Smith, 1999; Smyth and Williamson, 2004). Bound by bureaucracy, HRECs' interpretation of research involving 'doing no harm' to people may place restrictive obligations on the researcher that curbs the exploration of ways to achieve substantive benefits and empowerment for the community they are researching.

\section{Ethical diversities - Aotearoa New Zealand}

Ensuring meaningful informed consent when researching in a New Zealand context necessitates researchers understanding the cultural context in which they conduct their study. In a New Zealand research context, it is essential to take regard of the Treaty of Waitangi. Hudson and Russell (2009) discuss the relevance of the Treaty of Waitangi to research ethics, noting that researchers who engage with Māori communities can be guided by the Treaty of Waitangi's principles of partnership, participation and protection. Foremost for indigenous people is to have control over research processes and reciprocity within the research relationship to ensure that benefits are realised for Māori communities (Berryman et al., 2013; Smith, 1999). Tauri (2014) and Berghan (2007) challenge universal ethics as being unresponsive to indigenous Māori issues since these suggest a single mainstream approach. This mainstream approach continues to establish a dominant group's knowledge, experience and culture as the universal norm. Therefore, minority group and indigenous practices and philosophies that sit outside of this framework are often minimalised and seen as 'non-ethical' by HRECs in the powerful position of approving or rejecting research proposals. From Coon's (1998) perspective, HRECs may be viewed as a social group that views their own ethical standards as universal, absolute and right. Therefore, when other groups' standards differ, they are viewed as abnormal or wrong standards. This is an example of a core method of dividing social groups while maintaining unity within their own group, which may be an unintended consequence of accepting a radical universalistic stance.

\section{Diana's research ethics case}

The second case presented here originates from a qualitative semi-longitudinal study currently being conducted by a Pākehā New Zealand female doctoral student researcher (Diana) in Aotearoa New Zealand. Her doctoral project involves four tertiary education institutions: a university, a polytechnic, an institute of 
technology and a wānanga. This is a collaborative project with indigenous Māori tertiary students participating in focus groups, repeated semi-structured interviews, conversations and e-mail correspondence. The research explores what effective transitions into tertiary education look like for Māori students. The following example illustrates universal principles meeting with diversity in research ethics as practised by Diana in the field:

A relationship of mutual trust had built up between Diana and her participants over time; the study spans four semesters, involving repeated interviews and focus groups. When beginning the first round of focus groups and interviews during the second year of the study, an existing study participant brought a new student to join the focus group. He remembered Diana mentioning in the previous year that she was considering recruiting some additional new students who met specific age criteria that was not being currently met by existing participants.

The formal (recorded) focus group discussion was to occur following an informal (non-recorded) lunch. During lunch, the existing student introduced the new student to Diana; it quickly became clear this student met the required age criteria and that she was very keen to participate in the research. Her decision was based on what she had previously discussed with the existing participants, explaining she had 'already heard all about the research'. Individual privacy and confidentiality are key components of universal principles, yet similarly to Mohamed's case above, the research participants were clearly at ease discussing the interview content among themselves.

Since this situation was unexpected, Diana did not have documentation at hand such as the participant information sheet, the participant letter or the participant consent form. All of these forms had been approved through the HREC and were required to be given to a potential participant prior to the study. Diana explained this to the new participant, who expressed a desire to participate in that day's focus group. Other participating students also indicated at lunch that they approved of her attendance. She then asked if Diana could later provide her with the forms to read and sign. Her decision was already made; signing the forms was merely seen as a (less important, slightly irritating) formality for her. If Diana had denied her from participating in the focus group because she had not yet signed the form, trust between Diana and the existing participant may have been broken, and it seemed likely that the new participant would have been far more reluctant to decide to continue with the research.

Following the focus group meeting when Diana was able to provide the documentation to the new participant, she signed the consent form. As with Mohamed, Diana did not want to break the trust of her participants and she tried as much as she could to conduct her study according to Māori cultural traditions by recognising the importance of oral consent, communal decision making (Cram, 2006; Gray et al., 2017), and at the same time not to divert from her institution's HREC 
requirements of gaining prior written informed consent. Gray et al. note that, 'a lot of emphasis is placed by the formal ethics process on having signed informed consent, but the benefit of the form being signed is in fact almost all with the researcher' (Gray et al., 2017: 37). Just like Mohamed, Diana relied on her personal research ethics, improvised on the spot in the field to adhere to universal principles of research ethics required by her institution, yet adjusted to the diversity of the cultural situation. This is an example of research using universalism with diversity.

\section{Limitations and strengths}

This qualitative study relates to the contextual nature of the findings, leaving readers to determine their relevance in other contexts. This article refers to two case studies that highlight the tension that exists when applying universal ethics to researching with cultural diversity. In both ventures, seeking and conducting ethical research presented challenges for the researchers. 'A research plan may be approved as ethical but may not prove to be practical when the researcher tries to enact it, thus necessitating modification and in some cases, going beyond orthodox methods' (Amundsen et al., 2017: 10).

\section{Conclusions}

This article is concerned with illustrating the inherent tension that exists for researchers wishing to follow universal ethics according to the mandates of HRECs and simultaneously research with cultural diversity. The purpose is not to criticise Aotearoa New Zealand HRECs that take the role of reviewing, approving or rejecting research proposals. Rather, we propose that HREC members who are deciding on whether the intended research will be completed in the right, rather than the wrong way, consider a hybrid approach of universality with diversity. Universality with diversity requires making room within a universal one-size-fits-all ethics approach for a deeper consideration of how cultural values and beliefs bear influence on the process of ethical deliberation. Universality with diversity argues for an approach that preserves the tension and insights of both universalism and relativism in order to proactively empower emancipatory research. Researchers working under the auspices of a New Zealand research institution who intend to research with communities that may have high levels of illiteracy (e.g. working overseas in a remote African village), or communities that may subscribe to a social or communitarian ethos (e.g. a Māori community on a marae) may co-construct more meaningful research knowledge through seeking oral consensus from the given group of people than individually written consent. Such situations call for HRECs to consider universalism with diversity. Cultural values and beliefs must bear influence on the 
process of ethical deliberation and enable researchers to not simply spare people from harm, but to empower them as the co-creators of knowledge for emancipatory outcomes. We conclude that one size does not fit all in the current landscape of research with people in Aotearoa New Zealand. HRECs may need to consider expanding their approach from universal ethical principles to make room for a more diverse interpretation of what is 'ethical research conduct'. We urge HRECs to consider making room within a universal one-size-fits-all ethics approach for diverse cultural values and beliefs that may influence the process of ethical deliberation. Universality with diversity preserves the tension and insights of both universalism and cultural relativism in order to proactively empower emancipatory research.

\section{Acknowledgements}

The authors wish to thank Professor Brian Findsen for his guidance.

\section{Declaration of Conflicting Interest}

The authors declare that there is no conflict of interest.

\section{Funding}

All articles in Research Ethics are published as open access. There are no submission charges and no Article Processing Charges as these are fully funded by institutions through Knowledge Unlatched, resulting in no direct charge to authors. For more information about Knowledge Unlatched please see here: http://www.knowledgeunlatched.org.

\section{Note}

1. Highly restricted organisations, isolated from the rest of the world, and operate with structured daily routines; See Goffman (1962) and Amundsen, Msoroka, \& Findsen (2017).

\section{References}

Ahmad K (2001) Drug company sued over research trial in Nigeria. The Lancet 358: 815.

Amundsen D, Msoroka M and Findsen B (2017) "It's a case of access": The problematics of accessing research participants. Waikato Journal of Education 22(4): 12-24.

Battin T, Riley D and Avery A (2014) The ethics and politics of ethics approval. Australian Universities Review 56(1): 4-12.

Berghan G (2007, September 3) Maori, ethics and health promotion. In: Ethics and evidence in health promotion symposium. Auckland, New Zealand: Health Promotion Forum \& Hauora, Auckland, Available at: http://hauora.co.nz/resources/GrantBerghanE_ESep07.pdf Berryman M, SooHoo S and Nevin A (2013) Culturally responsive methodologies. Bingley: Emerald.

Blackmer J (2010) The ethical obligations of researchers in protecting the rights of human research subjects. World Medical and Health Policy 2(3): 88-93.

Brody B (2010) The continuing importance of the Declaration of Helsinki. World Medical and Health Policy 2(3): 94-96.

Chandler D and Munday R (2016) A dictionary of media and communication. Oxford: Oxford University Press. 
Coon CS (1998) Humanistic ethics. Available at: http://www.progressivehumanism.com/ progressive-humanism/humanist-ethics/ (accessed 7 May 2017).

Coram S (2011) Rethinking indigenous research approval: The perspective of a 'stranger'. Qualitative Research Journal 11(2): 38-47.

Cram F (2006) Talking ourselves up. AlterNative 2(1), 29-43.

Davies NECG and Karstaedt AS (2012) Antiretroviral outcomes in South African prisoners: A retrospective cohort analysis. PLoS ONE 7(3), 1-6.

Donnelly J (1984) Cultural relativism and universal human rights. Human Rights Quarterly 6(4): 400-419.

Edwards S (2012) New rules for research ethics committees. Research Ethics 8(1): 3-5.

Fromm E (2006) Man for himself: An inquiry into the psychology of ethics. Oxford: Routledge.

Goffman E (1962) Asylums: Essays on the social situation of mental patients and other inmates. Chicago: Aldine.

Gray B, Hilder J, Macdonald L, et al. (2017) Are research ethics guidelines culturally competent? Research Ethics 13(1): 23-41.

Gyekye K (2010) African ethics. Available at: https://plato.stanford.edu/entries/african-ethics/ (accessed 10 April 2017).

Hudson M (2004) He Matatika Māori: Māori and ethical review in health research, Masters Thesis, Auckland University of Technology, New Zealand. Available at: http://aut.researchgateway. ac.nz/bitstream/handle/10292/151/HudsonM.pdf;sequence=1 (accessed 14 June 2017).

Hudson M and Russell K (2009) The treaty of Waitangi and research ethics in Aotearoa. Bioethical Inquiry 6(1): 61-68.

Ikingura JKB, Kruger M and Zeleke W (2007) Health research ethics review and needs of institutional ethics committees in Tanzania. Tanzania Health Research Bulletin 9(3): 154-158.

Institute of Medicine (2007) Ethical considerations for research involving prisoners. Washington, DC: The National Academies Press.

International Theological Commission (2009) In search of a universal ethic: A new look at the natural law. Available at: http://www.vatican.va/roman_curia/congregations/cfaith/cti_documents/rc_con_cfaith_doc_20090520_legge-naturale_en.html (accessed 18 May 2017).

Johnson MG and Symonides J (1998) The Universal Declaration of Human Rights: A history of its creation and implementation 1948-1998. Paris: UNESCO.

Koster R, Baccar K and Lemelin R (2012) Moving from research ON, to research WITH and FOR Indigenous communities: A critical reflection on community-based participatory research. The Canadian Geographer 56(2): 192-210.

Marshall PA (2007) Ethical challenges in study design and informed consent for health research in resource-poor settings. Special Topics in Social, Economic and Behavioural (SEB) Research report series; No. 5, TDR/SDR/SEB/ST/07 1.Geneva: WHO. Available at: http://apps.who. int/iris/bitstream/10665/43622/1/9789241563383_eng.pdf (accessed 17 May 2017).

McMillan J and Conlon C (2004) The ethics of research related to health care in developing countries. Journal of Medical Ethics 30(1): 204-206.

Melé DN and Sánchez-Runde C (2013) Cultural diversity and universal ethics in a global world. Journal of Business Ethics 116(4): 681-687.

Mika CTH (2015) The thing's revelation: Some thoughts on Māori philosophical research. Waikato Journal of Education 20(2): 61-68.

Mkhize N (2006) Communal personhood and the principle of autonomy: The ethical challenges. Continuing Medical Education 26(1): 26-29.

Mokgatla B, IJsselmuiden C, Wassenaar D, et al. (2017) Mapping research ethics committees in Africa: Evidence of the growth of ethics review of health research in Africa. Developing World Bioethics. Epub ahead of print 3 May 2017. DOI: 10.1111/dewb.12146. 
Mutenherwa F and Wassenaar DR (2014) Ethics review of social and behavioural research in an African context. In: Kruger M, Ndebele P and Horn L (eds) Research ethics in Africa: A resource for research ethics committees. Stellenbosch: Sun Media, pp. 116-124.

The National Commission for the Protection of Human Subjects of Biomedical and Behavioral Research [NCPHSBBR] (1976) Report and recommendations: Research involving prisoners. DHEW Publication No. (OS) 76-131 Bethesda: NCPHSBBR.

Ndebele P, Mwaluko G, Kruger M, et al. (2014) History of research ethics review in Africa. In: Kruger M, Ndebele P and Horn L (eds) Research ethics in Africa: A resource for research ethics committees. Stellenbosch: Sun Media, pp. 3-10.

Nordenstam T (1968) Sudanese ethics. Uppsala: Nordiska Afrikainstitutet.

Nygard R and Saus M (2016) Emphasizing indigenous communities in social work research ethics. International Social Work 59(5): 666-678.

Onuoha C (2007) Bioethics across borders: An African perspective, Uppsala: Uppsala University.

Simons H and Usher R (2012) Introduction: Ethics in the practice of research, In: Simons H and Usher R (eds) Situated ethics in educational research. Hoboken: Taylor \& Francis, pp. $1-11$.

Singer P (1994) Ethics. Oxford: Oxford University Press

Singham M (2006) Multiculturalism in New Zealand - The need for a new paradigm. Aotearoa Ethnic Network Journal 1(1): 33-37.

Smith L (1999) Decolonizing methodologies: Research and indigenous peoples. London: Zed Books.

Smyth M and Williamson E (2004) Researchers and their 'subjects': Ethics, power, knowledge and consent. Bristol: The Policy Press.

Statistics NZ (2013) 2013 Census QuickStats about national highlights. Available from http://www. stats.govt.nz/Census/2013-census/profile-and-summary-reports.aspx (accessed 2 June 2017).

St Johns University of Tanzania (2013) Regulations on ethics in research. Dodoma: St Johns University of Tanzania.

Tanida N (1996) 'Bioethics' is subordinate to morality in Japan. Bioethics 10(1): 201-211.

Tauri J (2014) Resisting condescending research ethics in Aotearoa New Zealand. AlterNative 10(2): 134-150.

The Republic of South Africa (2015) Ethics in health research: Principles, processes and structures. Cape Town: Department of Health.

Tolich M (2002) Pākehā "paralysis": Cultural safety for those researching the general population of Aotearoa. Social Policy Journal of New Zealand 19: 164-178.

Tolich M (2016) A narrative account of ethics committees and their codes. New Zealand Sociology 31(4): 43-55.

United Nations [UN] (2015) Universal Declaration of Human Rights (UDHR). New York: United Nations.

Wasunna C, Tegli J and Ndebele P (2014) Informed consent in an African context. In: Kruger M, Ndebele P and Horn L (eds) Research ethics in Africa: A resource for research ethics committees. Stellenbosch: Sun Media, pp. 57-62.

Wilson K and Wilks J (2013) Research with indigenous children and young people in schools: Ethical and methodological considerations. Global Studies of Childhood 3(2): 142-152.

World Health Organisation [WHO] (2009) Research ethics committees: Basic concepts for capacity-building. Geneva: WHO.

World Medical Association [WMA] (2008) World Medical Association Declaration of Helsinki: Ethical principles for medical research involving human subjects. Helsinki: WMA. 